\title{
A retrospective study of 100 cases of ectopic pregnancy: clinical presentation, site of ectopic and diagnosis evaluation
}

\author{
Manthan Patel*, Dolly Chavda, Shetal Prajapati
}

Department of Obstetrics and Gynecology, P.D.U. Medical College, Rajkot, Gujarat, India

Received: 23 September 2016

Accepted: 20 October 2016

\section{*Correspondence:}

Dr. Manthan Patel,

E-mail: drmanthanpatel111gmail.com

Copyright: () the author(s), publisher and licensee Medip Academy. This is an open-access article distributed under the terms of the Creative Commons Attribution Non-Commercial License, which permits unrestricted non-commercial use, distribution, and reproduction in any medium, provided the original work is properly cited.

\begin{abstract}
Background: Over the last few decades, the incidence of ectopic pregnancy has increased almost to the extent of an epidemic disease. Ectopic pregnancy is one of the commonest acute abdominal emergencies. Ectopic pregnancy remains the leading cause of maternal deaths in early pregnancy. The aim of the study was the clinical presentations, ultra sound features and diagnostic difficulties of all cases of ectopic pregnancy.

Methods: This is a retrospective study conducted at Government Medical College and Hospital, Rajkot from January 2013 to June 2016, in the three and half year study period, there were a total of 100 ectopic pregnancies.

Results: Most common symptom in our study was lower abdominal pain, in $90 \%$ cases. Amenorrhea was present in 100 cases, whereas vaginal bleeding in 48 cases. Nausea, vomiting observed in $26 \%$ of patients, cervical tenderness in $48 \%$, and adnexal tenderness in $40 \%$ while shock was observed in $10 \%$ of patients.

Conclusions: Ampullary part of the fallopian tube is the most common site of ectopic pregnancy observed during our study. Complex adnexal mass was the most common finding on ultrasound. Surgical management by laparotomy and salpingectomy continues to be the preferred mode of management of ectopic pregnancy in our institution.
\end{abstract}

Keywords: Complex adnexal mass, Ectopic pregnancy, Laparotomy

\section{INTRODUCTION}

An ectopic pregnancy is one in which the fertilized ovum becomes implanted in a site other than the normal uterine cavity. ${ }^{1}$ over the last few decades, the incidence of ectopic pregnancy has increased almost to the extent of an epidemic disease. Ectopic pregnancy is one of the commonest acute abdominal emergencies. ${ }^{2,3}$ Ectopic pregnancy remains the leading cause of maternal deaths in early pregnancy. ${ }^{4}$ There is an overall increase in incidence of ectopic tubal pregnancy (ETP) and this is probably due to increased awareness, advanced diagnostic tools like transvaginal ultrasonography and estimation of beta subunit of human chorionic gonadotrophin $\left(\beta\right.$-hCG) in serum. ${ }^{5}$ Several risk factors for ectopic pregnancy have been identified including pelvic inflammatory disease, smoking, and, previous ectopic pregnancy. 4,5

\section{Aims and objectives}

Clinical manifestations may be diverse and diagnosis of this condition is often mistaken and delayed leading to increased morbidity and even mortality in these patients This study was undertaken to study the clinical presentations, ultra sound features and diagnostic difficulties of all cases of ectopic pregnancy that presented to our centre over a period of three and half years.

\section{METHODS}

This is a retrospective study conducted at Government Medical College and Hospital, Rajkot from January 2013 to June 2016. All women who presented to our hospital with ectopic pregnancy were analysed from the available hospital documents (bedside records, history, and 
operation theatre records). The data collected was in respect to the following:

1. Age

2. Parity

3. Chief complaints

4. Period of amennorhea

5. Any risk factors for ectopic pregnancy

6. Evidence of hypovolemia

7. Ultrasonographic Features

8. Operative findings

The data was analysed with simple descriptive statistics and presented in presented as percentages in charts and tables.

\section{RESULTS}

In the three and half year study period, there were a total of 100 ectopic pregnancies.

Table 1: Distribution of age.

\begin{tabular}{|l|l|}
\hline Age (years) & $\mathbf{N}=100$ \\
\hline$<20$ & 12 \\
\hline $21-25$ & 42 \\
\hline $26-30$ & 30 \\
\hline $31-35$ & 12 \\
\hline$>36$ & 04 \\
\hline
\end{tabular}

Age ranged from 18 to 40 years. Mean age was 26.38 years. Around $84 \%$ of cases from 21-35 years.

Table 2: Parity distribution in present study.

\begin{tabular}{|ll|}
\hline Parity & $\mathbf{N}=\mathbf{1 0 0}$ \\
\hline Nulliparous & 26 \\
\hline Primi & 26 \\
\hline Second & 28 \\
\hline Third & 12 \\
\hline Fourth & 02 \\
\hline Fifth & 02 \\
\hline
\end{tabular}

Parity ranged from nulliparous to $6^{\text {th }}$ parity. $26 \%$ cases were nulliparous, $26 \%$ with parity 1,28 cases with parity 2 and 12 cases with parity 3 . Mean parity was 1.5 .

Most common symptom in our study was lower abdominal pain, in $90 \%$ cases. Amenorrhea was present in 100 cases, whereas vaginal bleeding in 48 cases.
Nausea, vomiting observed in $26 \%$ of patients, cervical tenderness in $48 \%$, and adnexal tenderness in $40 \%$ while shock was observed in $10 \%$ of patients.

Table 3: Clinical features at presentation.

\begin{tabular}{|ll|}
\hline Clinical features & $\mathbf{N}=\mathbf{1 0 0}$ \\
\hline Abdominal pain & 90 \\
\hline Nausea, vomiting & 26 \\
\hline Vaginal bleeding & 48 \\
\hline Cervical tenderness & 48 \\
\hline Adnexal tenderness & 40 \\
\hline Guarding, rigidity & 12 \\
\hline Giddiness & 10 \\
\hline Shock & 10 \\
\hline
\end{tabular}

Classic triad of pain, bleeding and amenorrhoea was seen in only 42 cases.

Table 4: Sites of ectopic pregnancy in patients who underwent surgery.

\begin{tabular}{|ll|}
\hline Site of ectopic pregnancy & $\mathbf{N}=\mathbf{1 0 0}$ \\
\hline Ampulla & 56 \\
\hline Fimbrial & 18 \\
\hline Isthmic & 14 \\
\hline Cornual & 09 \\
\hline Rudimentary horn & 02 \\
\hline Abdominal & 01 \\
\hline
\end{tabular}

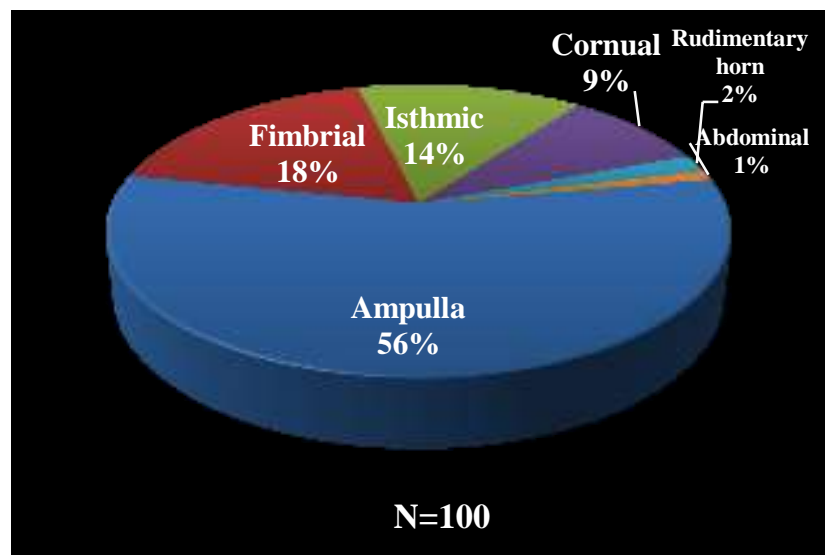

Figure 1: Sites of ectopic pregnancy.

Ampullary part of the fallopian tube is the most common site of ectopic pregnancy observed during our study, followed by fimbrial, isthamic and cornual pregnancy.

Table 5: Relation of amenorrhea to different sites of tubal ectopic pregnancies in present study.

\begin{tabular}{|lllllllll|}
\hline Days of Amenorhea & Total cases & Ampullary & Isthmic & Cornual & Fimbrial & $\begin{array}{l}\text { Rudimentary } \\
\text { horn }\end{array}$ & $\begin{array}{l}\text { Abdominal } \\
\text { pregnancy }\end{array}$ \\
\hline 29-42 days & 19 & 08 & 06 & 01 & 04 & 00 & 00 \\
\hline 43-56 days & 56 & 40 & 02 & 04 & 10 & 00 & 00 \\
\hline 57-70 days & 25 & 08 & 06 & 04 & 04 & 02 & 01 \\
\hline Total cases & 100 & 56 & 14 & 09 & 18 & 02 & 01 \\
\hline
\end{tabular}


Table 6: Ultrasound features of ectopic pregnancy.

\begin{tabular}{|l|l|}
\hline Ultrasound features & $\mathbf{N}=\mathbf{1 0 0}$ \\
\hline Complex adnexal mass & 82 \\
\hline Significant free fluid & 54 \\
\hline Hyperechogenic tubal ring & 20 \\
\hline
\end{tabular}

Complex adnexal mass was the most common finding, seen in 82 cases. Power Doppler showed increased vascularity in 27 cases on sonogram. 54 cases did have significant free fluid. Live fetal pole seen in 10 cases.

\section{DISCUSSION}

Ectopic pregnancy is an increasingly common and potentially catastrophic condition. Misdiagnosis of ectopic pregnancy is quite common. Delayed diagnosis may endanger the life of the patient but also decreases later the likelihood of a future successful pregnancy. ${ }^{6}$

There are a very few other disorders in obstetrics that has so many different presentations. The presentation of the patient may vary, some with minimal symptoms to a patient in a state of shock with massive haemoperitoneum. Some may present as a case of mass abdomen as in chronic ectopic. Vasomotor symptoms causing vertigo and syncope may be the presenting complaint.

Ectopic pregnancy is a nightmare to the patient and also to the treating obstetrician. In the present study the majority of the patients belonged to the age group 21-25 years. This is similar to the study by Rakhi et al and Poonam et al, in which the peak age incidence was 20-25 years. ${ }^{7}$ This is in contrast to the study by Arup Kumar et al in which the most common age group affected were $26-30$ years $(68.57 \%)^{8}$

Various studies have showed the symptom of abdominal pain was seen in $70.97 \%$ to $97.3 \%$ of the patients. In the study by Hassan $\mathrm{N}$ et al, abdominal pain was seen in (44) $70.97 \%$, amenorrhea (32) $51.61 \%$ and irregular vaginal bleeding (16) $25.81 \% .9$ In the study by Shaikh BN et al, typical history of amenorrhea and abdominal pain was found in $46(77 \%)$ women, $23(38 \%)$ were in a state of shock. ${ }^{10}$

Majority, $80.6 \%$ (75/93) presented with abdominal pain and $35.8 \%$ (33/93) presented with vaginal bleeding in study by AO Igwegbe et al. ${ }^{11}$ In study by Perveen $\mathrm{F}$ et al, common presenting symptoms were amenorrhea and abdominal pain, both found in $27(81.8 \%)$ patients and vaginal bleeding was present in $9(27.3 \%)$ cases. $^{12}$ In contrast the study by Mishra $\mathrm{S}$ et al. most of the cases presented with lower abdominal pain (93.54\%) followed by amenorrhea $(79.03 \%) .{ }^{13}$ In the study by Shivakumar $\mathrm{HC}$ et al, of the symptoms $95 \%$ had pain abdomen, $80 \%$ had amenorrhea, $70 \%$ had bleeding per vaginum, 30\% had vomiting and $5 \%$ had urinary complaints. ${ }^{14}$ In study by Shah $\mathrm{N}$ et al, among the clinical features, the most common presenting symptom was abdominal pain in 37 (97.3\%) patients whereas history of amenorrhea and vaginal bleeding were found in $28(73.6 \%)$ and 22 $(57.8 \%)$ patients respectively. ${ }^{15}$

In comparison to all these studies the present study had $90 \%$ of the patients had pain abdomen, $48 \%$ had vaginal bleeding, $48 \%$ had cervical tenderness and $26 \%$ had nausea and vomiting. Fainting and syncopal attack were present in $10 \%$ of the patients. Most of the cases presented with ruptured ectopic pregnancy making the scenario clear that still in India most of the patients present late, may be due to failure of making early diagnosis at various level of healthcare delivery system. As a result in our study majority of the women $(66.67 \%)$ had a laparotomy because of unstable condition and hemoperitoneum. Laparotomy with salpingectomy was the most common modality of treatment in most of the other studies.

In a 10 year population based study of 1800 cases of ectopic pregnancy, Bouyer et al., suggested sites of ectopic pregnancy as ampullary $(70 \%)$, isthmic $(12 \%)$, fimbrial $(11 \%)$, interstitial $(2.4 \%)$, ovarian $(3.2 \%)$ and abdominal $(1.3 \%){ }^{3}$ The results of our study are comparable. However there were no cervical or ovarian pregnancies in our series. Our study also had 2 cases of rudimentary horn pregnancy. In our study, tubal rupture occurred in $56 \%$ of patients. Rate of tubal rupture varies greatly between various studies from $16 \%, 36 \%$, $83.1 \% .^{16-18}$

Most of our patients belong to low socio economic status, thin built with pre-existing anemia, living in remote areas and being referred from, nearby government hospitals with established diagnosis of ectopic pregnancy. Around half of the patients were hemodynamically unstable at presentation. In our series laparotomy was the preferred mode of surgery in the presence of hemodynamic instability and previous surgery.

The decision to perform conservative versus radical tubal surgery is on the basis of patients' history, desire for future fertility and surgical findings.

Since most of our patients were referred with established signs of ruptured tubal pregnancy, and hemodynamic compromise, they needed emergency laparotomy and salpingectomy as life saving measures. High index of suspicion and awareness among clinicians, early use of routine transvaginal ultrasound to locate pregnancy and measuring hCG levels in any women in reproductive age who present with abdominal pain and vaginal bleeding, irrespective of amenorrhea is vital in diagnosing ectopic pregnancy at an early stage. This allows medical management and conservative tubal surgery with better reproductive potential. 
Strength of this study is that all the data were collected by the principle investigator. Clinical data and surgical notes were complete in all cases. Surgical specimens of all cases were confirmed by histopathological study. Limitations of this study are that secondary data was collected retrospectively. Random sampling could not be adopted due to lack of proper follow up. Future prospective studies comparing different surgical techniques and fertility outcome and studies to analyze cases of sterilization failure are beneficial).

\section{CONCLUSION}

Incidence of ectopic pregnancy has increased over past few years. Around 84\% of cases from 21-35 years. Most common symptom in our study was lower abdominal pain, in $90 \%$ cases. Amenorrhea was present in 100 cases, whereas vaginal bleeding in 48 cases. Ampullary part of the fallopian tube is the most common site of ectopic pregnancy observed during our study. Complex adnexal mass was the most common finding on ultrasound. Surgical management by laparotomy and salpingectomy continues to be the preferred mode of management of ectopic pregnancy in our institution.

Funding: No funding sources Conflict of interest: None declared

Ethical approval: The study was approved by the Institutional Ethics Committee

\section{REFERENCES}

1. Kumar P, Malhotra N. Ectopic pregnancy. Jefcoat's principles of Gynecology. 2008;142-59.

2. Challoner K, Incerpi M. Non traumatic abdomino surgical emergencies in the pregnant patients. Emerg Med Clin North Am. 2003;21(4):971-85.

3. Maymon R, Shulman A, Maymon BB, Bar-Levy F, Lotan M, Bahary C. Ectopic pregnancy, the new gynaecological epidemic disease: review of the modern work up and the non surgical treatment option. Int J fertile. 1992:37(3):146-64.

4. Department of Health. Why mothers die: a confidential enquiry into the maternal deaths in the United Kingdom. In Drife J, Lewis G (eds): Norwich, UK: HMSO. 2001;282.

5. Chatterjee S, Dey S, Chowdhury RG. Ectopic pregnancy in previously infertile women-subsequent perregnancy outcome after laparoscopic management. Al A meen J Med Sci. 2009;2(1):6772.
6. Jones EE. Ectopic pregnancy: Common and some uncommon misdiagnosis. Obstet Gynecol Clin North Am. 1991;18:55-72.

7. Poonam Y, Uprety D, Banerjee B. Ectopic pregnancy-two years review from BPKIHS, Nepal. Kathmandu University Med J. 2005;3:365-9.

8. Rakhi, Mital PL, Nupur H, Agarwal A, Makkar P, Fatima A. Ectopic pregnancy: a devastating catastrophe. Sch J App Med Sci. 2014;2(3A):903-7.

9. Hassan N, Zaheen Z, Jatoi N. Risk factors, clinical presentation and management of 62 cases of ectopic pregnancy at tertiary care centre. JLUMHS. 2009;8(3):238-41.

10. Shaikh NB, Shaikh S, Shaikh F. A clinical study of ectopic pregnancy. J Ayub Med Coll Abbottabad. 2014;26(2):178-81.

11. Igwegbe AO, Eleje GU, Okpala BC. An appraisal of the management of ectopic pregnancy in a Nigerian tertiary hospital. Ann Med Health Sci Res. 2013;3(2):166-70.

12. Perveen F, Tayyab S. Ruptured ectopic pregnancy: clinical presentation \& management. J Surg Pak. 2007;12(2):47-51.

13. Mishra S, Chaudhary V, Kaul Rajesh. Analysis of 62 cases of ectopic pregnancies in a rural medical college set up at Nalgonda Telangana, India. Int J Sci Study. 2015;3(6):103-6.

14. Shivakumar HC, Umashankar KM, Ramaraju HE. Analysis of forty cases of ectopic pregnancies in tertiary care hospital in South India. Indian J Basic Appl Med Res. 2013;3(1):235-41.

15. Shah N, Khan NH. Ectopic pregnancy: presentation and risk factors. J Coll Physicians Surg Pak. 2005;15(9):535-8.

16. Langer R, Bukovsky, Herman A. Conservative surgery for tubal pregnancy. Fertil Steril. 1982;38:427.

17. Deanna D, Caminiti MD, Kathleen L. Smith. An institutional review of the management of Ectopic pregnancy. J Gynecol Surg. 2006;22(2):47-56.

18. Lawani OL, Anozie OB, Ezeonu PO. Ectopic pregnancy: a life threatening gynecological emergency. Int J Women's Health. 2013;19(5):51521.

Cite this article as: Patel M, Chavda D, Prajapati S. A retrospective study of 100 cases of ectopic pregnancy: clinical presentation, site of ectopic and diagnosis evaluation. Int $\mathbf{J}$ Reprod Contracept Obstet Gynecol 2016;5:4313-6. 